\title{
EL OCASO DE LAS NACIONES-ESTADO CASOS Y HECHOS
}

José Domingo Begazo Villanueva*

E-mail:d180045@yahoo.es

Ricardo Torres Agurto ${ }^{\text {*** }}$

E-mail: agurtord@yahoo.es

\section{RESUMEN}

Somos hijos del pasado siglo y del milenio pasado; fuimos amamantados en una Sociedad Industrial, con sus propias inquietudes y paradigmas y con sus mismas organizaciones e instituciones. Hoy nos desenvolvemos en una Sociedad del Conocimiento donde el valor reside en otros conceptos, otras actitudes y también en otras configuraciones referentes al concepto de Nación y Estado.

Palabras clave: Sociedad del Conocimiento, Estado, Nación-Estado, Estado Región.

\section{ABSTRACT}

We are children of the past century and the last millennium, we were suckled in an Industrial Company, with its own anxieties and paradigms, and the same organizations and Institutions. Today we unfold in a Knowledge Society, where the value resides in other concepts, other attitudes and also in other referring configurations to the concept of Nation and State.

Key words: Knowledge Society, State, Nation-State, Region-State.

* Doctor en Administración. Magíster en Administración con mención en Informática de Gestión y en Desarrollo Económico Social. Conferencista invitado en diversos eventos realizados fuera del país. Profesor Principal de la Facultad de Ciencias Administrativas (UNMSM). Premio Mérito Científico UNMSM.

** Estudios de Maestría en Administración con mención en Dirección de Recursos Humanos. Sociólogo. Docente Universitario y Asesor en Gestión y Planificación Educativa Superior. 


\section{LA CRISIS DE LOS ESTADOS}

Hace pocos meses se realizó en el Perú la Cumbre América Latina, el Caribe y la Unión Europea (ALC-UE), que alguien denominó como el "Sindicato de los Países" ante la presencia de las grandes transnacionales que "sin patria, sin Dios y sin bandera" lo único que les interesa son las ganancias, el dios crematístico. Es así que ahora las empresas se mueven en nuevos escenarios como:

- La expansión global de las mismas que desborda las administraciones públicas.

- El endeudamiento creciente que hizo que los gobiernos fueran subordinados ante los mercados financieros.

- La desocupación, el empobrecimiento, la concentración de ingresos y la marginalidad urbana.

- La inseguridad urbana, fenómeno de crisis ante el cual se da el repliegue del Estado (del Estado-benefactor al Estado-regresivo) y la marginalidad, como consecuencia de la desocupación y el empobrecimiento.

- Descomposición cultural.

\section{LA NATURALEZA DEL ESTADO}

Para A. Toffler, en su libro "La Creación de una Nueva Civilización", el Estado del presente siglo, está definido por el fin del Estado-Nación o Nación-Estado que sirvió de marco jurídicoadministrativo de los pueblos, algo que tiempo atrás nadie habría imaginado ya que los conceptos de Nación-Estado son constructos imaginarios, son marcos virtuales de relaciones entre unos y otros pueblos; es decir, son patrones imaginarios, y la esencia de esos acercamientos tiene que estar en los pueblos reales, más aún en las personas reales. Por otro lado, las bases políticas y económicas de las naciones actuales se difuminan y cada vez son menos importantes los mercados locales en los cuales, atávicamente, se sustentaban.

El poder de los Estados futuros provendrá de poderes extra-estatales ya sea empresariales, religiosos o de asociaciones civiles, cada vez más fuertes. La producción de bienes es cada vez más supranacional. Se da la patética paradoja de que mientras los Estados-pobres (caso Perú) se sienten cada vez más soberanos, los Estados consolidados pierden cada vez más su identidad y su poder como tales. Su soberanía se ha internacionalizado. La de los pobres se ha diluido.

\section{HACIA LOS ESTADOS REGIÓN}

Quienes tomarán las decisiones serán los gobiernos regionales aliados con las empresas multinacionales. Serán, según palabras de A. Toffler: "Un archipiélago de tecnología avanzada en el mar de una humanidad empobrecida".

El movimiento mundial de personas entre países fue de 25 millones de personas en 1950; en la actualidad es de 900 millones. Es un hecho que los Estados tradicionales han erosionado la base en la que descansaban: el sentido de pertenencia de sus ciudadanos. Dentro de poco tiempo no se podrán cerrar fronteras ni para el paso de las personas ni para el paso de los productos; será entonces cuando el imaginario del Estado enfrentará el desafío que imponen las barreras actuales, para que los ciudadanos obtengan conciencia de su propia libertad, ya que el Estado será algo siempre virtual y mutante.

Hay una predicción de Ernesto Sábato, también expresada por Alvin Toffler, sobre las guerras del futuro, las cuales no serán entre Estados sino entre empresas privadas.

\section{NUEVAS NACIONES, NUEVAS REGIONES, NUEVOS ESPACIOS}

Boutros Ghali, ex-Secretario General de las Naciones Unidas, afirmó que si la autonomía de los Estados avanza al ritmo de los últimos años podrían haber 350 países en el año 2010.

Sin embargo, así como aparecen nuevos países, se habla de la posibilidad de que desaparezcan otros. Rank Corporation, un organismo asesor del Pentágono, organizó un seminario sobre la emergencia de aparición y desaparición de Estados.

A. Toffler también nos recuerda que un tercio de los miembros de las Naciones Unidas se encuentran, en estos momentos, amenazados por significativos conflictos rebeldes, por posiciones geográficas, nacionalistas, independentistas, culturales, étnicas, religiosas o simplemente desquiciadores per se.

El centro se ha desmoronado, los mejores ya no tienen convicciones, y los peores están repletos de apasionada intensidad. Desde la disolución de la Unión Soviética, la predisposición de los Estados a ser autónomos gana cada vez más polémicas. En la actualidad, podemos ver la fragmentación acelerada de muchos de los Estados que fueron 
las primeras Ciudades-Estados de los inicios de la civilización (Atenas, Roma, Cusco, etc.). Veamos algunos ejemplos:

- La Unión Europea. En1957 fue creada la Unión Europea en un tratado suscrito entre seis países, iniciando un creciente cogobierno entre sus miembros que hoy suman 27 . Ahora tienen un Parlamento Europeo, normas que acatan en forma conjunta y moneda y bandera única.

- Chechenia. Ubicada en una región montañosa del Cáucaso, tiene $13 \mathrm{mil} \mathrm{km}^{2}$ de extensión. A fines de octubre de 1991 proclamó su independencia mientras la Unión Soviética se desintegraba, oponiéndose los rusos con el argumento de que Chechenia estaba dentro de la jurisdicción rusa. Los chechenios, de religión musulmana, son uno de los pueblos más antiguos en el Cáucaso, cadena montañosa entre Azerbaiyán, Armenia, Georgia y Rusia.

- China. Se transformará en cientos de pequeñas Ciudades-Estado, según el vice Primer Ministro de Singapur.

- Checoslovaquia. Tuvo una división a lo "checoslovaca" que alude a la separación en enero de 1993 del antiguo Estado comunista en dos: la República Checa y Eslovaquia, en un proceso pacífico acordado por los dos gobiernos pero sin que sus pueblos manifestaran su voluntad en un referéndum. Esto puso fin a 41 años de dominio absoluto del régimen comunista.

- Yugoslavia. La lucha entre serbios (limpieza étnica), macedonios (católicos) y croatas (musulmanes), donde también existe la guerrilla de etnia albanesa del Ejército de Liberación de Presevo, Medvedja y Bujanovac (UCPMB).

- Filipinas. El grupo musulmán separatista Abu Sayyaf actúa en Limuton, en la isla de Basilan, a unos $910 \mathrm{~km}$ al sur de Manila. Pretende implantar un régimen fundamentalista y su forma de operar es capturar rehenes y después irlos ejecutando. Este grupo fue el que ejecutó al peruano norteamericano Guillermo Sobero en mayo del 2001.

- Birmania. Allí se encuentran los musulmanes en medio de una nación budista o la nación Tuareg, que busca su unidad cultural, nacional y política aunque sus habitantes son ciudadanos de países tan diferentes como Malí y Zaire.

- Yemen del Sur. Busca separarse de Yemen del Norte y los disentimientos entre Corea del Norte y Corea del Sur (paralelo 38).
- Liberia. País de África occidental que sufre una sangrienta guerra. Agreguemos a Sudán, otro país africano que se desangra en luchas tribales y que es motivo de preocupación de líderes mediáticos (cantantes y actrices) más que de los políticos. A esto agregamos que el Perú tiene una misión de militares Cascos Azules en esos territorios en estos momentos.

- India. Los estados de Nueva Delhi y Cachemira están en conflicto porque buscan su independencia. En las ciudades de Gujarat y Panvad las turbas hindúes atacan a musulmanes y centenares de personas han muerto en ataques incendiarios, tiroteos y puñaladas, y aunque sus tradiciones y estatus social sean todavía el faro de sus acciones como ocurre en Nueva Delhi, jóvenes de castas diferentes no se pueden casar. Aunque la ley actual prohíbe el sistema de castas, en la práctica éste subsiste; los Brahmanes se consideran la casta más elevada, los más virtuosos, sabios y cultos. Luego vienen las castas intermedias: los Kxatriyas y la Casta Jat (castas guerreras), los Vaisyas o comerciantes y agricultores. Por último, los Sudras, los "impuros", que realizan los trabajos más humildes. Un sacerdote brahmán se considera deshonrado si un sudra se le acerca a menos de veinte pasos o si su sombra cae sobre él.

- Israel. Estado fundado en 1948. Utiliza su potencial bélico de helicópteros y misiles contra los palestinos, que responden con sus bombas humanas, generándose una espiral de violencia en el Medio Oriente con un aumento de la intensidad de odio y combate, y la paz es el único camino que tardará muchos años en ser encontrado. Para darnos un ejemplo vemos que la Comisión de Educación y Cultura del parlamento israelí (Knéset) declaró persona no grata al director de orquesta Daniel Baremboim (judío-argentino) por haber dirigido una obra del músico alemán Richard Wagner.

- Argelia. El grupo islámico armado GIA apela a la violencia terrorista desde 1992, luego que el gobierno controlado por los militares desconociera el triunfo del Frente Islámico de Salvación en las elecciones generales de ese año. Su accionar homicida ha provocado desde entonces la muerte de unas 30,000 personas.

- Italia. Se pretende la división del país para dar una respuesta política a las reivindicaciones 
de autonomía de las prósperas regiones del norte de Italia. Padana, que se extiende a través de gran parte del norte de Italia, es la región de aquellos que favorecen la secesión, o al menos una Italia federalista que llaman el Norte. Los habitantes de Padania, que es el nombre del valle del Po, afirman que ese es el nombre de la nación liguista. A diferencia de los independentistas catalanes, vascos, galeses o escoceses, la Liga es anti-Unión Europea, muy conservadora en lo económico y social y muy hostil frente a los inmigrantes de las zonas pobres de su país y, especialmente, a los del Tercer Mundo (planteando incluso deportar o recluir en campos a muchos de ellos). Hoy ésta se ha convertido en el mayor aliado de Berlusconi a quien empuja más hacia la derecha. No se pretende crear una frontera entre las dos Italias pero tampoco quieren que el norte siga pagando el asistencialismo meridional.

Italia no es un país unido; es conocida la aversión que profesan los del norte hacia los del sur a quienes llaman "terrones", usando una voz despectiva para referirse a los paisanos que están debajo de Roma y que viven sumidos en la pobreza, conviven con las mafias, y siguen severos códigos de honor. En 1996 Italia celebró sus cincuenta años como república, celebración donde la Liga del Norte, de tendencia secesionista, tomó juramento a su autodesignado gobierno, con sede en la ciudad norteña de Mantua.

- Bélgica. Los partidos valones, de habla francesa, se oponen al fantasma de una partición del país en un estado flamenco y otro de habla francesa, pero la situación ya está planteada. Está en proceso de desintegración ya que los partidos flamencos han prometido avances en la autonomía de las provincias del norte para hacerse con el creciente voto nacionalista.

- Irlanda del Norte. Pese a los esfuerzos de los gobiernos británico e irlandés que elaboraron un plan de paz, éste nunca se ejecutó porque el Ejército Republicano Irlandés (IRA) ha rechazado entregar sus armas y llegar al desarme total y la desmilitarización del Ulster. Al mismo tiempo grupos de extremistas protestantes realizan protestas en Belfast e insultan y aterrorizan a los padres católicos que llevan a sus hijas a una escuela primaria, a la cual se llega cruzando a través de un barrio protestante. Los protestantes fueron otrora dominantes en
Irlanda del Norte y piden que se respeten sus derechos civiles y religiosos.

- Francia. Córcega ha pedido su separación de Francia.

- España. El grupo separatista vasco conocido como ETA (Euskadi Ta Askatasuna, Patria Vasca y Libertad), es el único grupo terrorista reconocido que opera en la Unión Europea. Con más de treinta años de creación y un millar de asesinatos en su sangriento historial, opera con sus coches bomba en Madrid. (Aeropuertos de Barajas y Málaga y plazas concurridas). Los terroristas etarras reclaman la independencia de las tres provincias del país vasco español (Guipúzcoa, Vizcaya y Álava), además de la comunidad autónoma española de Navarra y las tres provincias del país vasco francés $(\mathrm{Zu}-$ beroa, Lapurdi y Benafarroa). Agreguemos a esto a los catalanes (Cataluña) y a los gallegos (Galicia) que también desean su autonomía e independencia.

- Gibraltar. Desea ser una Ciudad-Estado en el seno de la Unión Europea. La Reina de Inglaterra seguiría siendo jefe de Estado, como es en el caso de Canadá y Australia. Según la actual constitución, los quince miembros de la Cámara Parlamentaria de Gibraltar tienen a su cargo la mayoría de los asuntos internos, mientras Gran Bretaña se ocupa de las relaciones exteriores, la defensa y la seguridad interna. La soberanía del estratégico peñón, ubicado en el extremo sur de España, es objeto de una disputa entre Madrid y Londres que ya ha durado varios siglos. España lo cedió a Gran Bretaña en 1713 en virtud del Tratado de Ultrech que puso término a la guerra de sucesión española; desde entonces, Madrid ha sostenido que firmó el pacto bajo coerción y que Gibraltar debe retornar a su poder.

- Canadá. Québec hizo un referéndum consultivo. El congreso canadiense declaró que la provincia de Québec constituía una nación dentro de la nación. Esta provincia francófona, que tiene cinco veces el tamaño de Francia y cuenta con una fuerza económica comparable a la de Bélgica, ha solicitado (de buenas maneras) independizarse de Canadá.

- Las Malvinas. Archipiélago austral que Argentina reclama como parte de su territorio, y que está bajo la posesión de Gran Bretaña desde 1883. En abril de 1982, Argentina y Gran 
Bretaña sostuvieron una guerra de 74 días por su posesión. Las Malvinas se ubican a $407 \mathrm{~km}$ de las costas argentinas; su superficie es de $12,173 \mathrm{~km}^{2}$ y alberga a una población de más de 2,000 habitantes.

- Colombia. Es el primer productor mundial de cocaína (con más de 120 mil has. de narcocultivos) y un importante proveedor de heroína está inmerso desde hace décadas en una sangrienta guerra de guerrillas. Las Fuerzas Armadas Revolucionarias de Colombia (FARC), de tendencia marxista, tienen una zona desmilitarizada de $42,000 \mathrm{~km}^{2}$ ubicada al sur del país, que controlan desde noviembre de 1998 , habiendo ganado mucho en el terreno militar ya que fortalecieron sus finanzas, reclutaron gente, y neutralizaron varios intentos de ataque del gobierno. Agregamos a esto el Ejército de Liberación Nacional (ELN) y los paramilitares de ultraderecha agrupados en la Autodefensas Unidas de Colombia (AUC) con unos 10,000 combatientes.

- Brasil. La industrializada ciudad de Sao Paulo, con la misma población que la que tiene todo el Perú, también ha dado visos de independencia y autonomía, ya que según ellos "mientras Rio baila, Sao Paulo trabaja”.

- Bolivia. Cuatro de los nueve departamentos de Bolivia, incluido el más rico de todos que es Santa Cruz de la Sierra, se declararon no sólo autónomos sino además regidos por estatutos que les reconocen facultades ejecutivas y legislativas. Detrás del conflicto pesan los prejuicios raciales. En Santa Cruz, poblada por un fuerte porcentaje de gente blanca conocida como los cambas, se cultiva el desprecio por quienes tienen ascendencia india, a quienes llaman collas. Además esa zona, posee los más grandes yacimientos de petróleo y gas, con reservas comprobadas de más de 60 trillones de $\mathrm{m}^{3}$ de gas, que pueden durar 200 años ${ }^{1}$. Asimismo los departamentos de Beni y Pando ya realizaron su consulta popular. Se especula que en América del Sur podría desaparecer Bolivia y sus regiones serían absorbidas por otros Estados debido a su mediterraneidad y a su debilidad económica, política y militar. No olvidemos que Argentina y Chile no tienen recursos energéticos que les permitan mantener su desarrollo y actualmente sufren de notable carencias. Y en esto tendremos que emplear no sólo la razón geopolítica o geoestratégica que les gusta emplear a los militares peruanos, sino también la geoeconomía y la biopolítica².

- Perú. Recientemente el Presidente de la Región Puno ha pedido una consulta pública para decidir su autonomía, lo cual ha llevado a que muchas autoridades políticas lo quieran desmentir. Puno es una región económicamente solvente; los une una raza: aymara y conservan su lengua materna. Se dice que su capital es Arequipa, (donde ha habido alcaldes de origen puneño) y que su playa es Tacna, y si caminamos por sus mercadillos de la Zona Franca veremos que la mayoría de ellos son propiedad de comerciantes puneños o alto andinos. Agregamos a esto que su cercanía con La Paz influye mucho, ya que la mayoría de su población es de origen aymara, entonces tenemos un buen polvorín por iniciarse que refuerzan su tentación independentista.

- Los Estados fuertes. A. Toffler anuncia que Estados fuertes como Alemania o Japón irán perdiendo importancia frente a pequeñas unidades territoriales económicas como el condado de Orange en California ${ }^{3}$; Osaka en Japón; la región de Lyón en Francia; y Ruhrgebiete en Alemania.

Se ha discutido que en Estados Unidos podrían tener autonomía diversos estados como California y Texas que han estado más ligados a la historia de México que a la de su vecino anglosajón, pero que ahora ni siquiera se sienten ligados a México.

1 Artículo de César Lévano publicado en Diario Libertad.

2 II Diplomado en Seguridad y Defensa Nacional. Marzo del 2008. Ministerio de Defensa y Universidad Nacional de Educación Enrique Guzmán y Valle.

3 California tiene un rol protagónico porque es la quinta economía del mundo, más grande que Francia, que Inglaterra y tiene mayor población que Canadá. Es el mercado más grande para productos americanos ya que Estados Unidos vende más al sur de la frontera que a Europa y Japón juntos. Por ejemplo, el mercado centroamericano representa 9 billones de dólares de ventas para Estados Unidos; o sea, más del total de exportaciones a India, Indonesia y Rusia combinadas. 


\section{CONCLUSIONES}

1. Desde el surgimiento del Estado-Nación moderno capitalista en Europa y los Estados Unidos, éstos han proliferado en América Latina, Asia, el Medio Oriente y África, surgiendo unos 140 nuevos Estados-Naciones.

2. Han aparecido y desaparecido decenas de países en el último siglo. De los 194 que están registrados en las Naciones Unidas, 32 tienen menos de veinte años. Sus fronteras están definidas al milímetro, aunque con frecuencia el sustento fue un mero dibujo caprichoso en el mapa ${ }^{4}$.

3. Muchos de estos Estados surgidos en el siglo XIX, después de un siglo y muchos decenios de independencia, tienen proyectos nacionales no completos y, en muchos de los casos, inviables, y se desarrollan bajo un gran atraso tecnológico, con regímenes o democracias de muy baja intensidad y de alta corrupción.

4. Según la CEPAL:

- 224 millones de personas viven en América Latina y el Caribe con menos de dos dólares al día. De éstas, 98 millones $(19.49 \%$ de la población) se encuentran en situación de pobreza extrema, viviendo con menos de un dólar al día.

- La pobreza afecta a los niños y jóvenes (entre 7 y 17 años) en mayor medida que a los adultos. Alrededor del $44 \%$ de todos los niños latinoamericanos son pobres, en comparación con el $28.6 \%$ de los adultos.

- El 10\% más rico de la población de América Latina y el Caribe se queda con el $48 \%$ del ingreso total, mientras que el $10 \%$ más pobre solo recibe el $1.6 \%$.
- Según el informe "Observatorio de la Globalización 2004”, en América Latina existen 22 billonarios (por ejemplo Carlos Slim) cuyas fortunas representan un alto porcentaje del PBI de sus países ${ }^{5}$.

5. Siempre se ha pensando que todos los EstadosNación se podían desarrollar; sin embargo, la experiencia de un siglo y más nos indica lo contrario y nos invita a pensar lo impensable: que muchos países mal llamados en desarrollo, no se están desarrollando, no están en vías de ser Newly Industrialized Countries (NIC) sino que, más bien, se están estabilizando como Economías Nacionales Inviables (ENI), hasta un punto en que nada funciona, la inviabilidad se agrava, crece la violencia y los estados subdesarrollados implosionan como Entidades Caóticas Ingobernables (ECI) ${ }^{6}$.

6. Cada vez son más las provincias ricas en todo el mundo que se están rebelando contra gobiernos ineficientes o despóticos, y estamos regresando a la consolidación de las Ciudades-Estado propias de la primera ola (Sociedad Agraria), pero también con sus propias configuraciones y sus deseos de ser actores con sus propias capacidades dentro del nuevo escenario mundial, alejado del concepto de Nación-Estado configurado y desarrollado en la segunda ola (Sociedad Industrial).

\section{BIBLIOGRAFÍA}

Begazo, José Domingo. Coetaneidad del Apocalipsis. Borrador de Libro.

De Rivero, Oswaldo. (2006). El mito del desarrollo. Los estados inviables en el Siglo XXI. Décima edición, Edit. Fondo de Cultura Económica.

Enríquez Cabot, Juan (2005). Los estados desunidos.

4 Richard Webb. Rincón del Autor. Diario El Comercio.

5 Guillermo Giacosa. Diario Peru21

6 Oswaldo de Rivero. (2006). El mito del desarrollo. Los estados Inviables en el siglo XXI. Décima edición. Edit. Fondo de Cultura Económica. 